\title{
Reversal of renovascular hypertension caused by nonspecific aortitis after corticosteroid therapy
}

\author{
T. P. Kulkarni, I. A. D'Cruz, M. J. Gandhi, and D. S. Dadhich \\ From the Department of Surgery and Medicine, Lokmanya Tilak Municipal General Hospital, and Medical \\ College, Sion, Bombay, and the Department of Cardiovascular Surgery and Radiology, Bombay Hospital and \\ Medical Research Centre, Bombay, India
}

Aortography in a I7-year-old girl showed nonspecific stenosing aortitis affecting the abdominal aorta, the renal arteries on both sides, and the left subclavian artery. The central aortic pressure was $180 / 115 \mathrm{mmHg}$. Prednisolone was administered for 8 months, and subsequently aortography was done annually on 3 occasions. This showed a pronounced regression in the stenotic lesions of the aorta and renal arteries; concomitantly the central aortic pressure returned to normal.

Renovascular hypertension secondary to nonspecific aortitis of unknown aetiology is not uncommon in India (Sen, I968; D’Cruz et al., 1970) and other Asian countries (Nakao et al., 1967; Danaraj, Wong, and Thomas, 1963; Vinijchaikul, 1967; Thenabadu, Rajasuriya, and Wickremasinghe, 1970). In our experience these patients usually present in the fibrotic end-stage of aortitis, at which time vascular surgery offers the only hope of cure (Sen, 1968; D'Cruz et al., I970); but in a few cases, as reported here, the diagnosis is made while the patient is still in the phase of active arteritis.

To our knowledge, regression of stenosis of the aorta or renal artery accompanied by a return of high blood pressure to normal, either spontaneously or after corticosteroid therapy, has never been documented previously.

\section{Case report}

A 17-year-old girl was referred to us in August 1969 with claudication in both lower limbs and the left upper limb. There were no other features apart from general weakness and malaise, and a febrile episode lasting for about a fortnight, one month previously.

On examination, very feeble pulses were felt in the left upper limb and both lower limbs. The blood pressure measured in the right arm was $110 / 70 \mathrm{mmHg}$. In the left arm and the lower limbs a very narrow pulse pressure of only a few millimetres of mercury was found; the systolic pressure in the left arm was $80 \mathrm{mmHg}$ and in both the legs I ro $\mathrm{mmHg}$. No other abnormal findings were detected on physical examination.

The electrocardiogram and chest $x$-ray were normal.
Red blood cell count $4,520,000 / \mathrm{mm}^{3} ; \mathrm{Hb}$ Io $\mathrm{g} / 100 \mathrm{ml}$, PCV 36 per cent; WBC: total $13,000 / \mathrm{mm}^{3}$, neutrophils 88 per cent (band forms $25.5 \%$, segmented forms $62.5 \%$ ), eosinophils I per cent, lymphocytes 5 per cent, monocytes 6 per cent. Bone marrow was essentially normal. ESR (Wintrobe) was $56 \mathrm{~mm}$, and on another occasion $60 \mathrm{~mm}$, after $\mathrm{I}$ hour. Blood examination was negative for LE cells. Serum proteins, total $7 \cdot 4 \mathrm{~g} / \mathrm{IO0} \mathrm{ml}$, by electrophoresis, albumin $2.5 \mathrm{~g} / 100 \mathrm{ml}$, total globulin 4.9 $\mathrm{g} / 100 \mathrm{ml}\left(\alpha_{1}\right.$ fraction $0.32 \mathrm{~g} / 100 \mathrm{ml}, \alpha_{2}$ fraction $\mathrm{r} \cdot 5 \mathrm{~g} / \mathrm{100}$ $\mathrm{ml}, \beta$ fraction $\mathrm{I} \cdot \mathrm{I} 2 \mathrm{~g} / \mathrm{I} 00 \mathrm{ml}, \gamma$ fraction $\mathrm{r} \cdot 96 \mathrm{~g} / \mathrm{I00} \mathrm{ml}$ ). Urine examination revealed nothing abnormal. Creatinine clearance was 147 1./24 hours. The radio-hippurate renogram was reported as suggestive of left renal artery stenosis.

An aortic arch angiogram was done on 24 September 1969 from the right brachial artery, using the Seldinger technique. The blood pressure, measured directly in the aortic arch on this occasion, was $180 / 115 \mathrm{mmHg}$. The aortogram demonstrated a left subclavian artery block at its origin (Fig. I), the distal portion of this artery being patent. The other arteries arising from the aortic arch were normal. The descending thoracic aorta was of normal calibre. Stenosis of the axillary or proximal brachial artery on the right side was presumed to exist, since a large gradient was found between the central aortic pressure and distal brachial artery pressure.

A week later an abdominal aortogram, by the percutaneous translumbar route, showed an elongated constriction of the abdominal aorta below the level of the renal arteries. There were two renal arteries on each side, and all four were narrowed at and near their origin (Fig. 2a).

Two weeks later, while under inpatient observation, the patient developed another episode of fever $\left(38.3^{\circ} \mathrm{C}\right)$ lasting 2 days, followed by a painful and tender enlargement of lymph nodes in the left submandibular and right 


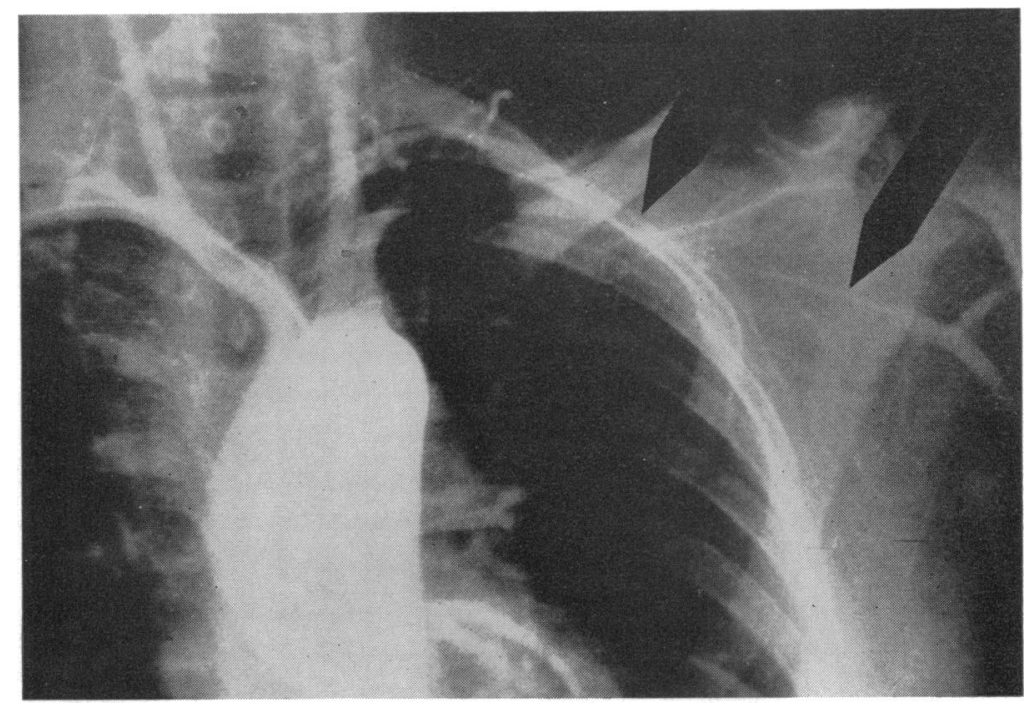

FIG. I Aortogram showing left subclavian artery, occluded at its origin, and distal narrowed segment (black arrows).

jugulodigastric regions. Biopsy of an inflamed left submandibular lymph node was reported on histologically as 'nonspecific chronic lymphadenitis'. The lymphadenitis subsided spontaneously over the next ro days without any specific therapy. No antituberculous chemotherapy was given.

Because of the high ESR and globulin levels suggestive of active arterial inflammation, prednisolone was administered in a daily dose of $20 \mathrm{mg}$ during the first month, is $\mathrm{mg}$ during the second month, and ro mg thereafter for the next 6 months.

The patient was next seen by us in October 1970, when aortography revealed a regression of the stenosis of the abdominal aorta as well as that of the renal arteries (Fig. 2b). The blood pressure, as measured directly in the upper abdominal aorta on this occasion, was $130 / 80$ mmHg.

Repeat aortograms in November I97I (Fig. 2c), and September 1972 (Fig. 2d) showed a further improvement in the calibre of the lower abdominal aorta and of the renal arteries.

\section{Comments}

Although the published reports on Takayasu's disease and nonspecific aortitis contain many a passing mention of corticosteroid therapy, there has been very little documentation of objective improvement in blocked or stenotic arterial lesions. In fact very little work has been published on the natural history of non-specific aortitis as revealed by serial aortography.

- Reporting on a joint study by several Japanese centres, Nakao et al. (1967) stated that cortico- steroids had been given to 29 of their 84 patients. Of these 29, 5 experienced 'remarkable clinical remissions', I3 'sufficient remissions', and II a 'poor effect'. The radial pulse 'became palpable' in 5 . According to Table 9 of Nakao's paper, aortographic evidence of 'remarkable effect' was present in 4 patients and of 'satisfactory effect' in 8 patients, but no specific mention was made of improvement in hypertension or amelioration of stenotic lesions affecting the abdominal aorta or its branches.

The ESR is a good indicator of inflammatory activity in nonspecific stenosing aortitis (Nakao et al., 1967). The fact that corticosteroid therapy can reverse arterial stenosis, as in our patient, suggests that it is worth a trial in every case with a high ESR, even when hypertension is present.

\section{References}

D'Cruz, I. A., Kulkarni, T. P., Gandhi, M. J., Juthani, V. J., and Murti, P. K. (1970). Aortitis of unknown etiology. Angiology, 21, 49.

Danaraj, T. J., Wong, H. O., and Thomas, M. A. (I963). Primary arteritis of aorta causing renal artery stenosis and hypertension. British Heart fournal, 25, 153.

Nakao, K., Ikeda, M., Kimata, S., Niitani, H., Miyahara, M., Ishimi, Z., Hashiba, K., Takeda, Y., Ozawa, T., Matsuchita, S., and Kuramochi, M. (1967). Takayasu's arteritis. Circulation, 35, II4I.

Sen, P. K. (I968). Obstructive disease of the aorta and its branches. Indian fournal of Surgery, 30, 289.

Thenabadu, P. N., Rajasuriya, K., and Wickremasinghe, H. R. (1970). Nonspecific arteritis of the aorta and its main branches. British Heart fournal, 32, 181 . 
Vinijchaikul, K. (1967). Primary arteritis of the aorta and its main branches. (Takayasu's arteriopathy.) American Fournal of Medicine, 43, 15.
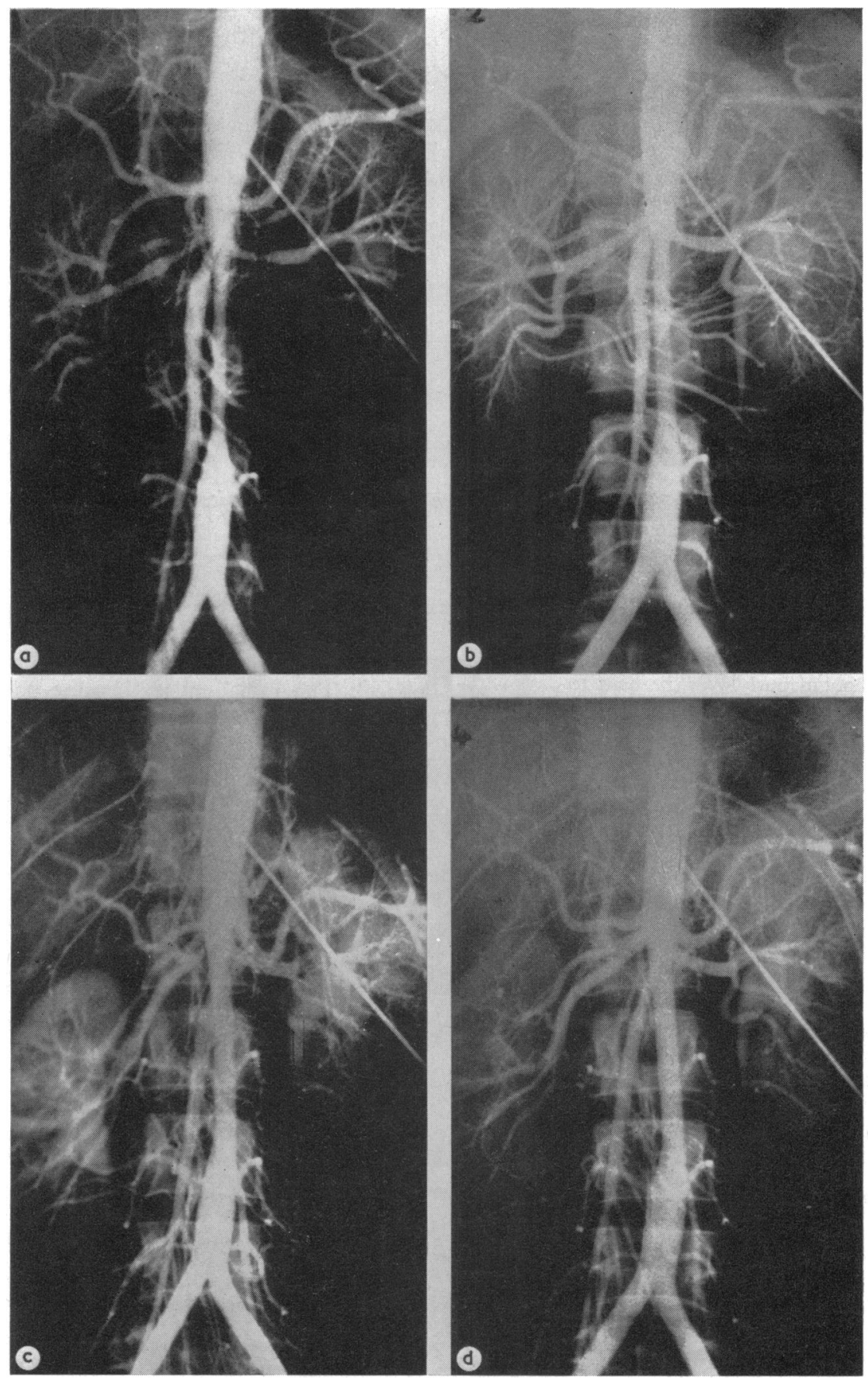

F I G. 2 Abdominal aortograms, a) in September 1969, showing elongated constriction of the aorta and stenosis of the renal arteries near their origin; b) in October 1970; c) in November 1971; and d) in September I972.

Requests for reprints to Dr. I. A. D'Cruz, Lokmanya Tilak Municipal General Hospital and Medical College, Sion, Bombay 400 022, India.

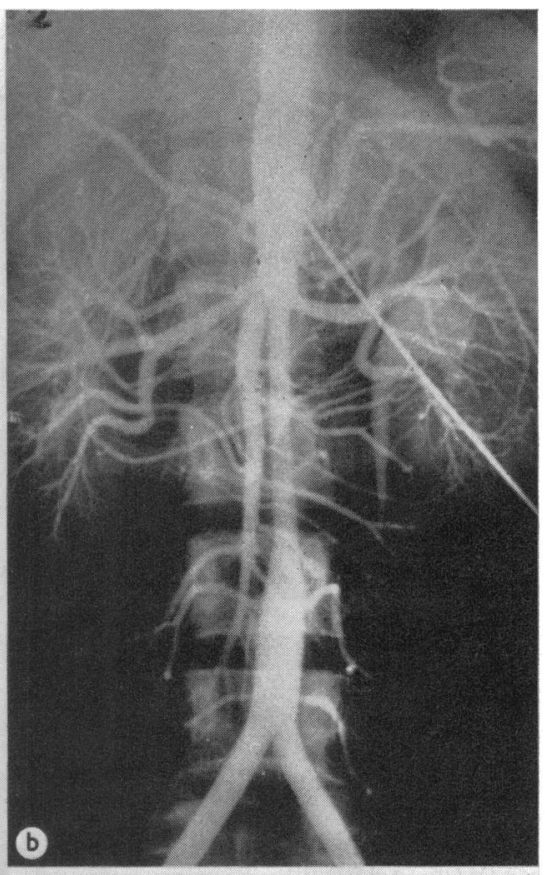

